\title{
$\infty$ Introduction
}

Given the importance of the concept of meaning to discussions of the arts and literature, and given the importance of the philosophy of Ludwig Wittgenstein to our understanding of that concept, it seems somewhat curious that scholars in aesthetics and literary theory have made no more use of Wittgenstein's potentially illuminating work than they have. In this book I attempt to do exactly that, in the hope of shedding some light on the relations between linguistic and artistic meaning, between understanding persons and understanding works of art, and between literary interpretation and philosophical analysis. I hope to achieve results more affirmative or positive in nature than those usually associated with philosophy and criticism of a broadly Wittgensteinian sort. Indeed, the Wittgensteinian tradition has often been construed as little more than a project of confusion-removal, which closes and narrows rather than opens and expands explanatory directions and possibilities. I have much more to say about the more affirmative and illuminating aspects of the Wittgensteinian tradition, and about the dubiousness of the distinction between constructive and critical methodological categories. At present, however, a few words are in order about how Wittgenstein's work has been 
received by those working within the disciplinary boundaries of aesthetics and literary criticism.

Wittgenstein's idea of family resemblance, as a contribution to the problem of universals, has been applied to the problem of definition in the arts, and this application has profoundly changed the expectations within aesthetics of how discussions of definition in the arts could proceed. ${ }^{1}$ Wittgenstein's work on aspect perception and the nature of imaginative seeing has also been applied to the study of the interrelations between the perceiver and the perceived, and this work has profoundly changed expectations within aesthetics of how discussions of those problems would proceed. ${ }^{2}$ And that seems to be the extent of the acknowledged significance of Wittgenstein's philosophy for aesthetic theory; the not-unreasonable consensusgiven the limited range of Wittgenstein's work that has been examined-is that this integration of Wittgenstein's influence has been completed and that the time has come to return to the fundamental task of theory construction. ${ }^{3}$ As I attempt to

1. See, for example, Morris Weitz, "The Role of Theory in Aesthetics," Journal of Aesthetics and Art Criticism 15 (Fall 1957), and "Wittgenstein's Aesthetics," in Language and Aesthetics, ed. B. R. Tilghman (Lawrence: University of Kansas Press, 1973).

2. See, for example, Virgil Aldrich, Philosophy of Art (Englewood Cliffs, N.J.: Prentice-Hall, 1963); Roger Scruton, Art and Imagination (London: Methuen, 1974); and John Casey, The Language of Criticism (London: Methuen, 1966).

3. See Maurice Mandelbaum, "Family Resemblances and Generalizations Concerning the Arts," American Philosophical Quarterly 2 (July 1965); George Dickie, Art and the Aesthetic (Ithaca: Cornell University Press, 1974); Ted Cohen, "The Possibility of Art: Remarks on a Proposal by Dickie," Philosophical Review 82 (1973): 69-82; and B. R. Tilghman, But Is It Art? (Oxford: Basil Blackwell, 1984). Further contributions to the investigation of the significance of Wittgenstein's philosophy for aesthetics are Richard Shusterman, "Wittgenstein and Critical Reasoning," Philosophy and Phenomenological Research 47 (September 1986); Richard Eldridge, "Problems and Prospects of Wittgensteinian Aesthetics," Journal of Aesthetics and Art Criticism 45 (Spring 1978); Carolyn Korsmeyer, "Wittgenstein and the Ontological Problem of Art," The Personalist 59 (April 1978); Roger A. Shiner, "The Mental Life of a Work of Art," Journal of Aesthetics and Art Criticism 4o (Spring 1982); Richard Wollheim, "The Art 
make clear in this book, I believe the story to be vastly more complicated, and very much more philosophically and critically illuminating, than such a truncated narrative of philosophical progress would suggest.

The story that follows resists encapsulation, but I can say at least that, first, it does not seem to me true that the two areas of impact just mentioned in fact capture what is of greatest significance in Wittgenstein's philosophy for aesthetics and, second, it accordingly does not seem to be at all obvious that postWittgensteinian aesthetic theory is wiser in the way it should be if it wants to proceed as it does. So, although I do raise the issues of definition and aspect perception in this book, central to it are, rather, Wittgenstein's investigations into the nature, or natures, of meaning, especially where those investigations bear directly on our understanding of artistic and literary meaning. Thus I discuss the extent and the limit ${ }^{4}$ of the relationship between aesthetic meaning and Wittgensteinian linguistic philosophy as well as the problems they have in common. I also try to sustain a sensitivity to the shaping influences on our

Lesson," in On Art and the Mind (Cambridge: Harvard University Press, 1974); P. B. Lewis, "Wittgenstein on Words and Music," British Journal of Aesthetics 17 (Spring 1977); Rush Rhees, "Art and Philosophy," in Without Answers (London: Routledge \& Kegan Paul, 1969); Frank Cioffi, "When Do Empirical Methods Bypass 'The Problems Which Trouble Us'?” in Philosophy and Literature, Royal Institute of Philosophy Lectures, Vol. 16, ed. A. Phillips Griffiths (Cambridge: Cambridge University Press, 1984); Peter Winch, "Text and Context," in Trying to Make Sense (Oxford: Basil Blackwell, 1987); R. K. Elliott, "Imagination in the Experience of Art," in Philosophy and the Arts, Royal Institute of Philosophy Lectures, vol. 6, ed. Godfrey Vesey (London: Macmillan, 1973); and the collections of papers in Inquiry 31 (December 1989), and New Literary History 19 (Winter 1988). Also, since I completed this book, two other works have appeared that explore directions similar to some of those I take in Chapters 1 and 2; these are Karlheinz Lüdeking, "Pictures and Gestures," British Journal of Aesthetics 30 (July 199o); and B. R. Tilghman, Wittgenstein, Ethics and Aesthetics (London: Macmillan, 1991).

4. See, for example, Richard Wollheim's discussion of the discontinuities between artistic and linguistic meaning in Painting as an Art (Princeton: Bollingen, 1987), esp. chaps. 1, 2, and 4 . 
thinking about these topics in the very formulation of those problems. What, however, can be said of an introductory nature from a somewhat lower altitude?

Throughout aesthetics and literary criticism the use of emotive-descriptive terms and the conjoined philosophical problem of justif ying such usage (where the fully articulated description of a work is often tantamount to a fully articulated interpretation of that work) have been undeniably central. Stated in terms that are familiar (but which are in fact, as we shall see, too philosophically stark to accommodate the facts of aesthetic practice), critical engagement with a work of art or literature generates descriptions that in turn demand justification; those then-justified descriptions, collected together, constitute an interpretation that should then (if we find the justification acceptable) shape our subsequent aesthetic experience.

The problem of justifying critical descriptions of a work, given form in this way, has led to ever more grand, and thus more general, theoretical construals of the relations between the critical perceptions in the mind of the beholder and the aesthetic object itself described by the articulation of those perceptions. This formulation of the problem presumes an aesthetic variant of metaphysical extensionalism, the belief that physical, extended objects are in both ontological and perceptual senses primary, so that we perceive only those objects directly or in an unmediated way; all other perceptions are thus taken to be indirect, mediated in a sense, and thus in need of justification. On this view, to put it simply, we see a bluishgreen, but we only infer the nonextended or nonphysical quality of emotional depth. We read the words on the page, we only infer the human seriousness of the story. We hear a move from $\mathrm{E}$ to E-flat, we inf er a darkening sense of foreboding. This view, which I hope to repudiate, has promoted ever greater levels of explanatory generality and an attendant disregard for detail, along with an insufficient grasp of the significance of 
such detail not only for critical practice but for the conjoined philosophical problem of critical justification.

In place of such an ascent to explanatory generality, we need, I believe, a descent, indeed of the sort exemplified in the late work of Wittgenstein, to the critically and aesthetically sitespecific, contextually grounded details that generate emotivedescriptive usages in the first place and that themselves justify (in, as we shall see, a noninferential way) those aestheticlinguistic practices. I attempt such a descent in Chapters 3, 4, and 5 of this book. First, however, I locate the ground, and this is the project of Chapters 1 and 2, in which I pursue Wittgenstein's answer to his own question that launched his later philosophy, "What is the meaning of a word?"

The Wittgensteinian analytical strategy of the languagegame, insofar as it affords an exquisitely detailed and controlled examination of the uses of words within delimited contexts, provides insight into expressive limits, stylistic integrity, organic cohesion, incremental developments of expressive capacities, and the instrumental employments of artistic materials within analogous aesthetic microcosms. In Chapter 1, I pursue such connections between the linguistic and the aesthetic, and this pursuit introduces the topics of Chapter 2, in which I first assemble an overview, a general conception, of the difficult phrase "a form of life" as it is employed in Wittgenstein's philosophy of language, and then proceed to a detailed consideration of cases within which thoughts and feelings are expressed in art as they are expressed through gesture and as they are embedded in ritualistic practices. The strikingly close relations, indeed the isomorphic parallels, between languagegames and artistic styles, and between a form of life and a collection of artistic practices, lend new and positive content to

5. This is of course the opening question of Ludwig Wittgenstein, The Blue and Brown Books (Oxford: Basil Blackwell, 1958), p. 1. 
the analogy between art and language, given a conception of language strikingly unlike those which have heretofore been influential—often misleadingly influential—throughout aesthetic theory. ${ }^{6}$ Taken together, then, the first two chapters are an attempt to respond to the need for a fairly detailed examination of Wittgenstein's later conception of linguistic meaning as a way of constructing a large-scale foundation for an understanding of Wittgensteinian criticism and literary epistemology. The particular issues that arise in these first chapters are the nature, scope, expressive limits, and expansions of language-games; the significance of context for meaning within language-games; the ideas of linguistic use, aim, and function and the significance of these for art; examples of artistic and literary language-games; linguistically engendered insights into aesthetic qualities such as coherence and inventiveness; the definition and understanding of the concept "form of life"; meanings resistant to propositional formulation and gestural significance; the notion of artistic "spirit"; aesthetic rule-following; and the relations between artistic uses and interpretative meaning.

In addition to answering the need for the descent to the level of detail, Wittgenstein's phrase "to imagine a form of life" carries an implicit invitation to turn to literary examples, which, with the particular case of the philosophical novelist Henry

6. I have discussed some of these conceptions of language as they have influenced aesthetic theory in a number of articles, to include: "Obviating Aesthetic Dualism," forthcoming in a collection on the work of Joseph Margolis edited by Lars Aagaard-Mogenson; "The Language of Feeling," forthcoming in the Journal of Aesthetics and Comparative Literature; "The Aesthetics of Indiscernibles," in Visual Theory: Painting and Interpretation (New York: Harper Collins, 1991), ed. Norman Bryson, Michael Ann Holly, and Keith Moxey; "Artistic Intention and Mental Image," Journal of Aesthetic Education 22 (Fall 1988): 6375; "Creation as Translation," Journal of Aesthetics and Art Criticism 46 (Winter 1987): 249-58; "Music and Imagination," Philosophy 61 (October 1986): 51317; "Art as Thought: The Inner Conflicts of Aesthetic Idealism," Philosophical Investigations 9 (October 1986): 257-93; and "Art and the Unsayable: Langer's Tractarian Aesthetics," British Journal of Aesthetics 24 (Autumn 1984): 325-40. 
James, ${ }^{7}$ the last three chapters of this book accept. Chapters 3 and 4 are investigations, via literary interpretation, into the varieties of linguistic meaning and the multiform moves made within the extended-yet-circumscribed language-games that constitute the Jamesian short story. The issues that arise here are the significance for linguistic philosophy of literary or, to be more specific, descriptively mimetic complexity; the circumstantial prerequisites for linguistic force; relations between aesthetic and ethical descriptions, by which I mean the very many ways we have of describing what we see in a work of art, what we see as the aesthetic aspects of an object or person, and what we see in the actions and the verbal and gestural expressions of a person that holds ethical value or significance; the fundamental analogies between the perception of works of art, of significant artifacts, and of persons; the misleading powerparticulary in aesthetic and literary-critical contexts-of the distinction between perception and description; the inability of linguistic atomism to serve as a theory of meaning "beneath" literary interpretation; the significance of tone and silence for linguistic meaning; the irreducible complexity of aesthetic and critical descriptions, which is shown by their refusal to settle into traditional philosophical distinctions such as mind and matter, self and other, emotion and reason, inner and outer, and intrinsic and relational; the critical inapplicability of the all-too-familiar additive model (text plus interpretation) and its relation to Wittgenstein's discussion of aspect perception; perceptions, descriptions, and interpretations of human facial expressions and the "logic" of understanding facial expressivity; and the irreducibility of an aesthetic phenomenon as complex as literary meaning.

In Chapter 5 I extend the project of philosophical investi-

7. For this dimension of James's work, see Renford Bambrough, "Ounces of Example," in Realism in European Literature: Essays in Honour of J. P. Stern, ed. Nicholas Boyle and Martin Swales (Cambridge: Cambridge University Press, 1986). 
gation through literary interpretation and attempt to show the contribution the Wittgensteinian method of investigation can make to a larger understanding of literature and its epistemological value. The issues that arise here are the problematic character of the distinction between philosophy as an analytical activity and philosophy as an interpretative or literary-critical activity; the pragmatic question of the significance for literarycritical practice of the Wittgensteinian analytical method; the limitations on criticál-methodological encapsulation; the antisystematic diversity exhibited by the word "knowledge" and some of the categories of its usage; the vast range separating the spoken from the unspoken with regard to what one knows; the weaving of a fabric of simulated knowledge or selfdeception; and, again, the prerequisite of detail to the achievement of a complex yet clarif ying overview of a philosophically problematic concept such as knowledge.

Anyone who has read Wittgenstein should of course be wary of generalizations and, for that matter, of general remarks about the danger of generalizations. Nevertheless, to describe this project in general terms: I attempt to identify and elucidate Wittgenstein's nonreductive and contextualist views on meaning which hold special significance for our understanding of the experience of art and literature, and to show that significance through close readings (in what is perhaps a newly articulated sense of that phrase) of a writer whose fiction is itself one kind of epistemology. 